\title{
Effect of Wide Ranges of Polarization and Concentration on the Behavior of Ferricyanide/Ferrocyanide Systems Studied Through Electrochemical Measurements
}

\author{
Moises Sanchez-Amaya ${ }^{1}$, Maximiliano Bárcena-Soto ${ }^{2}$, René Antaño-López ${ }^{3}$, Aaron Rodríguez-López ${ }^{4}$, \\ Jose Angel Barragan ${ }^{1}$, Alberto Gutierrez-Becerra ${ }^{5}$, Erika Roxana Larios-Durán ${ }^{1, *}$ \\ ${ }^{1}$ Departamento de Ingeniería Química, Universidad de Guadalajara, C.P. 44430 Guadalajara, Jalisco, \\ México \\ ${ }^{2}$ Departamento de Química, Universidad de Guadalajara, C.P. 44430 Guadalajara, Jalisco, México \\ ${ }^{3}$ Centro de Investigación y Desarrollo Tecnológico en Electroquímica, S. C., C.P. 76703 Pedro \\ Escobedo, Querétaro, México \\ ${ }^{4}$ Universidad Politécnica de Santa Rosa Jáuregui, C.P. 76220 Querétaro, Querétaro, México \\ ${ }^{5}$ Departamento de Ciencias Básicas y Aplicadas, Universidad de Guadalajara, CUTonalá, C.P. 45452 , \\ Jalisco, México \\ *E-mail: erika.lduran@academicos.udg.mx
}

Received: 10 September 2021 / Accepted: 27 October 2021 / Published: 6 December 2021

\begin{abstract}
The ferricyanide/ferrocyanide system has been historically utilized as an electrochemical standard under typical conditions, including dilute concentrations and narrow polarization ranges. Although deviations in the system's reversibility have been reported in broader experimental conditions, an electrochemical study that integrates the factors related to its idealities and nonidealities for an improved understanding of this redox couple has not been conducted. Therefore, in this paper, the electrochemical behavior of this system is investigated on a platinum electrode using $0.1 \mathrm{M} \mathrm{K}_{2} \mathrm{SO}_{4}$ as the supporting electrolyte under general experimental conditions at three $\mathrm{K}_{4}\left[\mathrm{Fe}(\mathrm{CN})_{6}\right] / \mathrm{K}_{3}\left[\mathrm{Fe}(\mathrm{CN})_{6}\right]$ concentrations $(1 \mathrm{mM}, 10 \mathrm{mM}$, and $0.1 \mathrm{M})$ and a widespread polarization potential range, which has not been conventionally reported. Through a literature review and the interpretation of cyclic voltammograms, double-layer capacitance polarization curves and electrochemical impedance spectra obtained under these conditions, a scheme of the global interfacial reactions involved in this system is proposed. As a result, a general approach to the mechanistic implications of the interfacial phenomena, including not only the reversible interfacial response but also the nonreversible behavior, is presented.
\end{abstract}

Keywords: Ferrocyanide/ferricyanide, Irreversibility of the system, Adsorbates on the electrode, Side reactions.

\section{$\underline{\text { FULL TEXT }}$}


(C) 2022 The Authors. Published by ESG (www.electrochemsci.org). This article is an open access article distributed under the terms and conditions of the Creative Commons Attribution license (http://creativecommons.org/licenses/by/4.0/). 